\title{
Currículo e Avaliação: um Mapeamento da Visão dos Professores de Educação Física Sobre as Competências Requeridas nos Principais Documentos Regulatórios
}

\section{Curriculum and Evaluation: a Mapping of the View of Physical Education Teachers on the Competencies Required in the Main Regulatory Documents}

\author{
Isis Kfouri Silva*a; Eliza Adriana Sheuer Nantes; ${ }^{\mathrm{a}}$ Samira Fayez Kfouri da Silva ${ }^{\mathrm{a}}$; Humberto José Carodoso Pianca ${ }^{\mathrm{b}}$ \\ annopar, Programa de Pós-Graduação Stricto Sensu em Metodologias para o Ensino de Linguagens e suas Tecnologias. PR, Brasil. \\ bUniversidade Estadual de Londrina, Programa de Pós-Graduação Stricto Sensu em Educação. PR, Brasil. \\ *E-mail: isisks@gmail.com
}

\begin{abstract}
Resumo
Este estudo objetivou mapear a visão dos professores sobre os objetivos e competências requeridas nos principais documentos regulatórios, no que tange à avaliação nas aulas práticas, na disciplina de Educação Física, na Educação Básica do Estado do Paraná, no Ensino Fundamental. Os pressupostos epistemológicos que sustentam este trabalho se ancoram em pesquisas, bem como nos documentos regulatórios do Brasil e do Paraná. Metodologicamente, realizou-se uma pesquisa de cunho qualitativo, com abordagem exploratória. Enquanto instrumento de pesquisa, utilizou-se o questionário, contendo questões abertas e fechadas. Os participantes da pesquisa foram 43 professores de Educação Física da Rede Estadual de ensino do Paraná, atuantes nos anos finais do Ensino Fundamental, alocados no Núcleo Regional de Educação de Londrina-PR. Ao final da pesquisa se conclui que, para avaliar a aprendizagem do aluno nas aulas práticas, de maneira que o ato de avaliar seja realmente uma ferramenta otimizadora do desenvolvimento da aprendizagem dos alunos, é fundamental que os professores conheçam e apliquem o que é estabelecido em torno do currículo apresentado nos documentos, sobretudo, nos objetivos evidenciados pelo Currículo da Rede Estadual Paranaense.
\end{abstract}

Palavras-chave: Ensino. Educação Física. Formação de professor.

\begin{abstract}
This study aims to map the teachers' view on the objectives and competencies required in the main regulatory documents related to practical classes evaluation in Physical Education discipline, in Elementary Education of Paraná State. The epistemological assumptions that support this study are used in research, plus the regulatory documents of Brazil and Paraná. Methodologically, a qualitative research was carried out, with an exploratory approach. As a research toll, a questionnaire was used, with objective and discursive questions. The research participants were 43 Physical Education teachers from the Paraná State educational network, active in the final years of Elementary Education, allocated at the Regional Education Center of Londrina-PR. At the end of the research, it was concluded that, in order to evaluate the student's learning in practical classes, as an optimizing tool for the student's learning development, it is essential that teachers know and apply what is already established around the curriculum presented in the regulatory documents, especially in the objectives evidenced by the Curriculum of Paraná State Network.
\end{abstract}

Keywords: Education. Physical Education. Teacher training.

\section{Introdução}

No Brasil, ao se proceder um estudo sobre o percurso educacional sócio-histórico se encontra que a educação é regida por documentos oficiais, sejam esses deliberações, diretrizes curriculares, instruções, leis, orientações gerais, pareceres, procedimentos, planos de trabalho docente e Políticas Nacionais de Educação, todos com o intuito de subsidiarem um projeto maior, que é denominado Projeto Político Pedagógico da Educação brasileira.

Todavia, o Brasil tem um aspecto peculiar que o diferencia de países como Portugal, França, Uruguai, Paraguai, entre outros, que é a extensão territorial. Logo, como assegurar que, independentemente, da região geográfica brasileira, o aluno tenha acesso a um direcionamento educacional similar? $\mathrm{Na}$ busca por delinear caminhos norteadores educaionais foi implantada a Base Nacional Comum Curricular - BNCC (BRASIL, 2018).
Na BNCC (BRASIL, 2018), embora não se encontrem autores explicitamente nominados, há um revozeamento epistemológico que sintetiza as discussões presentes na última década, entre essas se tem a indicação de ações teóricopráticas voltadas para a aprendizagem ativa do aluno, tendo como ponto de partida os conhecimentos prévios e, para tanto, um caminho profícuo é a realização de avaliações diagnóticas, ação está já preconizada pelos estudos de Kenski, Oliveira e Clementino (2006), Hoffmann, (2009) e Luckesi, (2011).

Outro exemplo que se pode citar é que a BNCC (BRASIL, 2018) pontua que se deve considerar, ainda, as experiências dos estudantes, independentemente, do Estado no qual ele esteja na esfera escolar, afinal o conhecimento engendra uma série de fatores, entre esses a trajetória de aprendizagem trilhada por cada aluno, ao longo de seu percurso de formação, o que é corroborado pelas pesquisas de Luckesi (2011).

Ademais, ao se trabalhar com a identificação de diagnóstico o resultado pode poporcionar uma base para 
planejamentos futuros, como ações educacionais em resposta às lacunas de aprendizagem dos alunos. Quando o diálogo é estimulado entre os educadores, a avaliação tem o poder de melhorar habilidades docentes e ajudar a escola como um todo, fortalecendo o aprendizado dos conteúdos curriculares e, ainda, a duração do seu alcance (DES, 1987).

No que tange à parte metodológica, a BNCC (BRASIL, 2018) norteia as ações docentes, no sentido de o professor explorar diferenciadas estratégias, tendo como ponto fulcral a reflexão, e esta pode ocorrer por meio de situações problema que sejam atraleladas à vivência do educando. Essa possibilidade de execução de tais propostas reflexivas já foram apresentadas, em estudos sedimentados, como os de Hoffman (2009), nos quais se encontra a ênfase de se considerar o contexto de cada lócus de atuação docente, ou seja, se deve priorizar a realidade escolar, antes de se propor ações interventivas.

No que diz respeito à postura do professor, Hoffman (2009) indica que ele seja um mediador, termo este que é espandido pela BNCC (BRASIL, 2018), pois o documento conclama o aluno a exercer, cada vez mais, o autodidatismo e sua autonomia.

Diante disso, se vê que a BNCC (BRASIL, 2018) assume o caráter de ser um documento norteador e com força de lei, no sentido de que deve ser estudado e executado na prática escolar em todo território nacional, logo, a compreensão do documento é essencial, uma vez que esse enreda uma série de competências específicas que devem ser contempladas no componente curricular de cada disciplina. Para isso, é premente a implemantação de ações didático-pedagógicas, que contemplem dois eixos: a especificidade das áreas e a interdisciplinaridade.

Nesse contexto, para que se contemple no componente curricular as especificidades de cada disciplina, conhecer o eixo norteador e fazer uma intersecção entre a teoria e a prática são ações prementes. Já no que tange à interdisciplinaridade, esta é possível promovendo-se maior articulação horizontal entre as áreas, de forma que sejam inplantadas ações dinâmicas, integradas, priorizando uma articulação horizontal, ou seja, devem ser priorizadas ações integradas, porém que mantenham uma progressão entre os anos iniciais e finais do Ensino Fundamental, priorizando dois eixos: os conhecimentos prévios dos alunos e as especifidades da disciplina a ser trabalhada.

Dentro desse contexto se encontra a disciplina que é o objeto desta investigação: Educação Física. Como as demais disciplinas, questões como implantar o currículo da escola e selecionar formas de avaliar o conteúdo são inerentes nessa área. Assim, a avaliação deve fazer parte desse processo, uma vez que possibilita que os objetivos educacionais sejam previamente elaborados, objetivos educacionais podem ser definidos e o processo de aprendizagem dos alunos mapeado e expressado.

A avaliação, fator importante do processo educacional, envolve nas aulas de Educação Física tanto a teoria quanto a prática, por isso se entende tratar de uma disciplina que tem suas especificidades. Principalmente, quando se refere à parte prática, pois, muitas vezes, a avaliação das atividades práticas tende a ser subjetiva e, por isso, pode ser entendida como um grande desafio para o professor, principalmente, na Educação Básica.

Em função do exposto, o estudo objetivou mapear a visão dos professores sobre os objetivos e competências requeridas nos principais documentos regulatórios, no que tange à avaliação nas aulas práticas, na disciplina de Educação Física, na Educação Básica do Estado do Paraná, no Ensino Fundamental.

\section{Material e Métodos}

A metodologia de pesquisa selecionada é a pesquisa qualitativa, conforme ancoragem nos pressupostos teóricos da pesquisadora Bortoni-Ricardo (2008). Os estudos da pesquisadora indicam que a pesquisa qualitativa deve privilegiar a compreensão e a interpretação dos dados à luz dos fenômenos sociais, dentro dos contextos em que ocorrem.

Quanto aos participantes da pesquisa foram elencados como critérios de participação atuar na rede estadual de ensino, junto aos anos finais do Ensino Fundamental ( $8^{\circ}$ e $9^{\circ}$ ano), dentro da cidade de Londrina-PR. Justifica-se a seleção do público-alvo em função de uma parceria entre essa equipe de pesquisadores e o Núcleo Regional de Educação de Londrina/ PR. Em seguida, submeteu-se a proposta de pesquisa para o Comitê de Ética em Pesquisa, sendo aprovada, conforme parecer $n^{\circ} 3.967 .398$, de 13/04/2020.

Para a coleta de dados, foram seguidas as proposições de Marconi e Lakatos (2003), elegeu-se a técnica da documentação direta, via observação direta extensiva, selecionando, como instrumento de coleta de dados, via questionário Google Docs.

$\mathrm{O}$ instrumento de pesquisa contém o total de 12 questões, constituído por uma série de perguntas direcionadas aos participantes e respondidas no tempo e local definidos por eles, o que permitiu menor grau de influência nas respostas ${ }^{1}$, enquanto recorte, foram selecionadas cinco questões para este trabalho, sendo essas: gênero; idade; tempo de atuação; conhecimento dos professores sobre competências/objetivos requeridos para o Ensino Fundamental da rede estadual paranaense, segundo documentos reguladores; relatos dos professores sobre o que conhecem sobre os objetivos/ competências requeridas nos documentos reguladores.

Assim, a fim de se mapear a visão dos professores sobre os objetivos e as competências requeridas nos documentos reguladores paranaense, no que tange à avaliação nas aulas

1 Questionário encaminhado por link, via WhatsApp, em um grupo de professores da Rede, em parceria com o Núcleo Regional de Educação Londrina/PR. 
práticas, na disciplina de Educação Física, foram deliberadas algumas categorias de análise que nortearão esta pesquisa.

Enquanto categoria de análise, os excertos das enunciações dos professores foram organizados, conforme orientações da Análise de Conteúdo (BARDIN, 2016). A autora destaca que a análise de conteúdo pode ser uma análise dos 'significados', por exemplo, a análise temática. Seria o pesquisador proceder uma análise dos 'significantes', podendo-se agrupar por temas afins, integrados na busca por responder ao objetivo da pesquisa (BARDIN, 2016).

Isso posto, considera-se "em análise de conteúdo, a mensagem pode ser submetida a uma ou várias dimensões de análise" (BARDIN, 2016, p. 148), logo, procede-se a uma categorização ${ }^{2}$ das respostas dos professores, agrupando as enunciações por traços de similaridade presentes nos posicionamento dos participantes. Essa categorização foi assim delineada:

I) discurso do professor versus documentos regulatórios do Estado do Paraná;

II) competências requeridas para aulas práticas de Educação Física.

\section{Resultados e discussão}

\subsection{Os Documentos Regulatórios e a disciplina de Educação Física}

Para essa seção foram selecionados alguns documentos, entre esses a BNCC (BRASIL, 2018), por ter abrangência nacional. Ademais, considerando que o recorte deste trabalho se centra nos professores do Estado do Paraná, elegeu-se, ainda, a inclusão das Diretrizes Curriculares do Estado do Paraná/DCE (PARANÁ, 2008) e do Referencial Curricular do Paraná, Currículo da Rede Estadual do Paraná/CREP (PARANÁ, 2019), sendo este publicado após a BNCC. Todos documentos terão como ponto de intersecção o diálogo com a disciplina de Educação Física, área na qual os docentes investigados atuam na Educação Básica.

Nesse contexto, a BNCC é o documento majoritário, e que os demais ficam sujeitos ao que é estabelecido nesse de maneira mais ampla. Conforme consta no texto da própria BNCC (BRASIL, 2018, p. 7), esse se trata de "[...] um documento de caráter normativo que define o conjunto orgânico e progressivo de aprendizagens essenciais que todos os alunos devem desenvolver ao longo das etapas e modalidades da Educação Básica", visando que sejam "assegurados seus direitos de aprendizagem e desenvolvimento, em conformidade com o que preceitua o Plano Nacional de Educação (PNE)".

Quanto à área de aplicação, a BNCC se aplica exclusivamente à educação escolar, tal como a define o $\S 1^{\circ}$ do
Artigo $1^{\circ}$ da Lei de Diretrizes e Bases da Educação Nacional (LDB, Lei no 9.394/1996), e está orientado pelos princípios éticos, políticos e estéticos que visam formação humana integral e à construção de uma sociedade justa, democrática e inclusiva, e a ancoragem para trais pressupostos, está fundamentada nas Diretrizes Curriculares Nacionais da Educação Básica - DCN (BRASIL, 2018).

É importante ressaltar que, apesar de finalizada apenas em 2017 e promulgada em dezembro de 2018, a BNCC já havia sido prevista na Constituição de 1988, mais especificamente no Art. 210, no qual consta que os conteúdos mínimos para o Ensino Fundamental seriam fixados, no intuito de "assegurar formação básica comum e respeito aos valores culturais e artísticos, nacionais e regionais" (BRASIL, 1988).

Da mesma forma, a Lei de Diretrizes e Bases da Educação (LDB) no 9394 do ano de 1996, também previa o conteúdo das bases, quando coloca, diretamente, que os sistemas de ensino poderão se compor de componentes curriculares da BNCC (Redação dada pela Lei no 13.415, de 2017) (BRASIL, 1996). Sendo assim, observa-se a importância deste documento, já citado em dois importantes marcos da história do Brasil.

Assim, de acordo com a BNCC (BRASIL, 2018), documento que estrutura e explicita as competências que devem ser desenvolvidas durante a Educação Básica, o que inclui os anos finais do Ensino Fundamental, a Educação Física é definida como uma competência específica do componente curricular da etapa do Ensino Fundamental, ciclo 2 , que se refere aos anos finais.

Em uma próxima seção, a BNCC considera a Educação Física uma disciplina da área de linguagens, já que eentre outros tipos, a disciplina pode ser entendida como uma linguagem corporal, sendo assim compreendida, logo é importante que o aluno se aproprie dessa linguagem, bem como das demais, que podem ser: verbal, visual, sonora e digital (BRASIL, 2018).

Antes de tratar das competências requeridas para a Educação Física, a BNCC (BRASIL, 2018, p. 63) traz quais são as competências específicas de linguagens para o Ensino Fundamental, tais como: a compreensão das linguagens, enquanto "construção humana, histórica, social e cultural", conclamando o professor a levar o aluno a "conhecer e explorar diversas práticas de linguagem", para isso, o documento indica que sejam trabalhadas ações metodológicas que piorizem ao aluno "defender pontos de vista, em prol dos direitos humanos; desenvolver o senso estético para reconhecer, fruir e respeitar as diversas manifestações artísticas e culturais", contemplando, ainda, o contexto digital, pois o documento indica que se deve "Compreender e utilizar

\footnotetext{
2 Conforme Bardin (2011), o método da Análise de Conteúdo envolve algumas fases: 1) a organização da análise (pré-análise, exploração do material e interpretação prévia dos dados); 2) a codificação (recorte das unidades de análise, agrupamentos quantitativos e qualitativos); 3) a categorização (classificação dos elementos para análise); 4) a inferência (estabelecimento de relações/conclusões a partir da interpretação dos dados). Embora, neste momento, tenha sido realçada a fase da categorização, é evidente que o estudo envolveu as demais etapas, uma vez que, antes desse processo, os dados foram devidamente compilados e previamente organizados. As inferências, por sua vez, serão apresentadas na seção seguinte, em que cada categoria será devidamente analisada.
} 
tecnologias digitais de informação e comunicação de forma crítica, significativa, reflexiva e ética nas diversas práticas sociais" (BRASIL, 2018).

Assumindo que o conceito de competências tem estreita relação com a definição de conteúdos, proposta por Coll et al. (2000 apud DARIDO; RANGEL, 2011), que corresponde às dimensões conceitual, procedimental e atitudinal dos fatos e conceitos, isto é, toda forma de conhecimento. Nesse sentido, desenvolver uma competência requer mobilizar conhecimentos, sejam esses conceituais ou procedimentais; habilidades práticas, cognitivas e socioemocionais; atitude e valores para resolver demandas complexas da vida cotidiana (BRASIL, 2018).

Isso posto, ao se considerar as competências específicas de Educação Física para o Ensino Fundamental, conforme a BNCC, tem-se o seguinte:

\begin{abstract}
1. Compreender a origem da cultura corporal de movimento e seus vínculos com a organização da vida coletiva e individual 2. Planejar e empregar estratégias para resolver desafios e aumentar as possibilidades de aprendizagem das práticas corporais, além de se envolver no processo de ampliação do acervo cultural nesse campo. 3. Refletir, criticamente, sobre as relações entre a realização das práticas corporais e os processos de saúde/doença, inclusive no contexto das atividades laborais.4. Identificar a multiplicidade de padrões de desempenho, saúde, beleza e estética corporal, analisando, criticamente, os modelos disseminados na mídia e discutir posturas consumistas e preconceituosas. 5. Identificar as formas de produção dos preconceitos, compreender seus efeitos e combater posicionamentos discriminatórios em relação às práticas corporais e aos seus participantes. 6 . Interpretar e recriar os valores, os sentidos e os significados atribuídos às diferentes práticas corporais, bem como aos sujeitos que delas participam. 7. Reconhecer as práticas corporais como elementos constitutivos da identidade cultural dos povos e grupos. 8. Usufruir das práticas corporais de forma autônoma para potencializar o envolvimento em contextos de lazer, ampliar as redes de sociabilidade e a promoção da saúde. 9. Reconhecer o acesso às práticas corporais como direito do cidadão, propondo e produzindo alternativas para sua realização no contexto comunitário. 10. Experimentar, desfrutar, apreciar e criar diferentes brincadeiras, jogos, danças, ginásticas, esportes, lutas e práticas corporais de aventura, valorizando o trabalho coletivo e o protagonismo (BRASIL, 2018, p.223).
\end{abstract}

Corroborando com Santos (2008), no que tange ser possível perceber que a Educação Física na escola vai muito além do foco tecnicista, que se estabeleceu ao longo do tempo, em que o importante era o "saber jogar" ou, de maneira geral, o "saber fazer". Além disso, o foco com relação às brincadeiras, aos jogos, às danças, aos esportes, etc, está relacionado a "experimentar, desfrutar, apreciar e criar" e não, necessariamente, ao saber fazer (BRASIL, 2018).

Diante da lei, o foco apenas tecnicista, além de inadequado, também é posto como insuficiente, o que já foi preconizado pelos estudos de Luckesi (2011). Entende-se, então, a necessidade de mudança e, que para isso se sedimente na prática, é preciso repensar as ações pedagógicas direcionadas à avaliação e às atribuições de resultados no processo de ensino e aprendizagem (BRASIL, 2018).

Outro documento, criado a partir da BNCC, é o Referencial Curricular do Paraná, do ano de 2018, em que o Estado do Paraná define os direitos e objetivos de aprendizagens para alunos da Educação Infantil e Fundamental, por meio do Programa de Implementação da BNCC.

Neste referencial se tem que, partindo da aprovação da BNCC pelo Conselho Nacional de Educação - CNE e homologação do Ministério da Educação - MEC, em 2017, foi definido um conjunto de aprendizagens que devem ser garantidas às crianças e jovens, por serem consideradas essenciais, especialmente, na Educação Infantil e Ensino Fundamental. Esse também explica que a etapa do Ensino Médio, apesar de apresentada ao MEC e CNE, ainda está em um período de realização de audiências públicas para que a participação coletiva seja garantida, na construção do documento referente a essa etapa, que é a última da Educação Básica (PARANÁ, 2018).

Na sequência, a partir do Referencial Curricular se tem, finalmente, em 2019, a apresentação do CREP. Este com a função de fornecer subsídios para as escolas, no sentido de revisarem seus currículos e elaborarem seus planejamentos. Conforme é possível observar no próprio documento, o mesmo apresenta sugestões de conteúdos para os componentes curriculares (o que muitos chamam ainda de "disciplinas"), para cada ano, e ainda indicando possíveis distribuições na organização do ano letivo.

No documento, os conteúdos são sugeridos com base nos objetivos apresentados no Referencial, ou seja, a partir de organizadores curriculares previstos anteriormente é que os conteúdos são estabelecidos, visando o desenvolvimento das competências gerais da Educação Básica, bem como características como conhecimento e repertório cultural, pensamento científico, crítico e criativo, comunicação, cultura digital, argumentação, relações entre trabalho e projeto de vida, etc, com fins de cidadania (PARANÁ, 2019).

Com base nisso, são apresentados quadros curriculares do $1^{\circ}$ ao $9^{\circ}$ ano - de cada componente curricular (disciplina), com colunas de unidades temáticas, objetos de conhecimento, códigos (para organização específica do documento), objetivos de aprendizagem, sugestões de conteúdo, divisões por trimestres.

Retomando o que foi dito no início desta seção, outro documento importante é o das DCE, que foi elaborado com base nas DCN (2013), do Ministério da Educação (MEC). O mesmo foi dito como paralelo, pois a partir da apresentação do BNCC em 2017, e do Referencial Curricular do Paraná, em 2018, as DCE passaram a atender somente o Ensino Médio, pois este não é contemplado no Referencial, ainda. Isso porque a elaboração do documento para o Ensino Médio se encontra “em discussão e análise” (PARANÁ, 2018, p. 9).

As DCE são um documento que a ser utilizado nas escolas públicas estaduais, no Paraná, como orientador da prática dos professores de todas as disciplinas, inclusive na Educação 
Física (PARANÁ, 2008). Apesar de ter sido publicado há mais de uma década, este documento já trazia a proposta curricular para o Ensino Fundamental e Ensino Médio (sendo que este último ainda permanece em vigência), em atendimento também ao que impõe a Lei de Diretrizes e Bases da Educação Nacional no 9.394/1996 (BRASIL, 1996).

Ao considerar ainda o que as DCE de Educação Física dizem sobre a avaliação, de forma mais ampla, tem-se a indicação de que se trata de um "processo educativo, a avaliação deve se fazer presente, tanto como meio de diagnóstico do processo ensino e aprendizagem quanto como instrumento de investigação da prática pedagógica”, de forma que possa assumir "uma dimensão formadora, uma vez que o fim desse processo é a aprendizagem, ou a verificação dessa, mas também permitir que haja uma reflexão sobre a ação da prática pedagógica" (PARANÁ, 2008, p. 31).

Nesse sentido, quando as DCE tratam particularmente da avaliação em Educação Física, vê-se que há uma concordância com os estudos de Santos (2008), sobretudo, no que tange às DCE pontuarem ser "necessário entender que a avaliação em Educação Física à luz dos paradigmas tradicionais, como o da esportivização, desenvolvimento motor, psicomotricidade e da aptidão física, é insuficiente para a compreensão do fenômeno educativo", isso dentro de uma "perspectiva mais abrangente" (PARANÁ, 2008, p. 75).

Explanados os principais documentos regulatórios da avaliação e o currículo do Estado do Paraná, por meio de objetivos e competências, é coerente se conhecer como se sucede a aplicação dos mesmos na prática docente.

\subsection{Ação docente frente aos documentos regulatórios}

A escola tem, entre as suas inúmeras tarefas, uma considerada essencial, a produção sistemática de conhecimento, por meio da criticidade, da inteligibilidade e da comunicabilidade das coisas e dos fatos. Nesse sentido, a ação docente deve ser pautada em oportunizar ao estudante, no processo ensino e aprendizagem (inclusive na avaliação), que compreenda a importância em assumir o papel de sujeito da produção de sua inteligência de mundo e não apenas o de receber o que lhe é transferido pelo professor (FREIRE, 1996).

A construção da visão de mundo do estudante está imbricada à maneira com que o mesmo é conduzido a produzir o conhecimento sobre as coisas, fatos e conceitos, e é dever legal, no que diz respeito à educação na Educação Básica, proporcionar-lhe o seu pleno desenvolvimento, prepará-lo para o exercício da cidadania, qualificação para o trabalho e para a progressão em estudos posteriores (FREIRE, 1996; BRASIL, 1988; BRASIL, 1996).

A função da escola, dentro deste contexto, está embasada na concepção de homem e de sociedade que se pretende formar e construir. Dessa forma, é importante compreender a educação como um fenômeno social que ocorre naturalmente nas interações sociais, promovendo as aprendizagens. Logo, a escola, por ser um constructo social e possuir uma função sociocultural, deve garantir aos estudantes o acesso aos saberes socialmente disponíveis, para isso, deve se pautar no currículo, visto ser esse uma parte fundante deste processo (PALMA, OLIVEIRA, PALMA, 2010; DARIDO, RANGEL, 2011).

A institucionalização da escola teve como premissa a continuidade de uma determinada cultura, a partir dos conhecimentos produzidos e acumulados pela humanidade e que precisam ser organizados para efeitos de ensino e aprendizagem. Contudo, alguns objetivos, intenções e interesses sociais são postos no currículo que, por sua vez, tem um texto 'pretensioso', isso porque busca reproduzir uma forma de compreender a realidade e, por mais que se discurse o contrário, o currículo sempre estará condicionado a um contexto histórico-social, porque é uma construção social, produzida por seres sociais e contextualizados, não sendo, portanto, neutro. Assim, a organização curricular e sua operacionalidade trazem, além de implicações didáticopedagógicas, implicações sociais, filosóficas e políticas" (PALMA, OLIVEIRA, PALMA, 2010, p. 21).

Dito com outras palavras, observa-se que há um discurso velado, isto é, na verdade não há neutralidade nas proposições que embasam a elaboração do currículo. Nesse sentido, evidencia-se que existe intencionalidade, principalmente, implícita na determinação dos saberes escolares e disciplinares por parte dos gestores, que comporão o currículo, fato que pode configurar nos aspectos individuais e coletivos da sociedade que se pretende construir.

A compreensão e a construção da realidade é reproduzida com base nos pressupostos da gestão democrática, sendo pautada na intencionalidade educativa e na autonomia de cada estabelecimento de ensino para elaborar o Projeto Político Pedagógico, que norteia e aglutina todos os aspectos do trabalho educativo da escola e tem a incumbência de elaborar e executar a sua proposta pedagógica, a qual expressa as concepções assumidas coletivamente e efetivadas na prática pedagógica, descritas no plano de trabalho docente, que corresponde ao planejamento da docência.

É imprescindível que os gestores educacionais, bem como os professores da Educação Básica tenham conhecimento sobre a base legal que disciplina a maneira como a educação deve ser conduzida nas diferentes esferas da organização administrativa da República Federativa do Brasil, uma vez que a partir desta base legal é que são elaboradas as diretrizes e documentos normativos da Educação Básica.

A BNCC, como já posto, é um documento de caráter normativo que define o conjunto orgânico e progressivo de aprendizagens essenciais, que todos os alunos devem desenvolver, ao longo das etapas, e modalidades da Educação Básica (BRASIL, 2018). Conforme definido na Lei de Diretrizes e Bases da Educação Nacional (LDB, Lei n ${ }^{\circ}$ 9.394/1996), a BNCC já estava preconizada, tendo o objetivo 
de conter um conjunto de orientações que visa nortear os currículos das escolas públicas e privadas de Educação Infantil, Ensino Fundamental e Ensino Médio, em todo o Brasil.

A BNCC estabelece direitos e objetivos de aprendizagem, isto é, o que se considera indispensável que todo estudante aprenda a cada etapa da Educação Básica. Estabelece, portanto, os conteúdos essenciais que deverão ser ensinados em todas as escolas, assim como as competências e as habilidades que deverão ser desenvolvidas pelos alunos (BRASIL, 2018).

\subsection{Dados coletados}

Entre as perguntas aplicadas no questionário, algumas dessas trazem informações que foram consideradas relevantes para elucidação das análises e discussões em torno da temática. Uma dessas é saber que os participantes da pesquisa foram em sua maioria, mulheres, ou seja, professoras de Educação Física do sexo feminino. Sendo, dos 43 participantes, 48,8\% homens e $51,2 \%$ mulheres.

A partir dessas informações, é possível confirmar o que considera Silva (2016), quando mostra que a partir de contextos sociais e culturais é que são influenciados os números de maior ou menor incidência de docentes do sexo feminino ou masculino nas escolas, e ao dizer que há aproximadamente 82,51\% mulheres no Ensino Fundamental no Brasil, ao passo que perto de $18,79 \%$ é a representação dos masculina nessa mesma etapa.

Perguntou-se também sobre a faixa etária dos participantes, conforme mostra o gráfico da Figura 1.

Figura 1 - Perfil - Idade dos participantes

Idade

(43 Respostas)

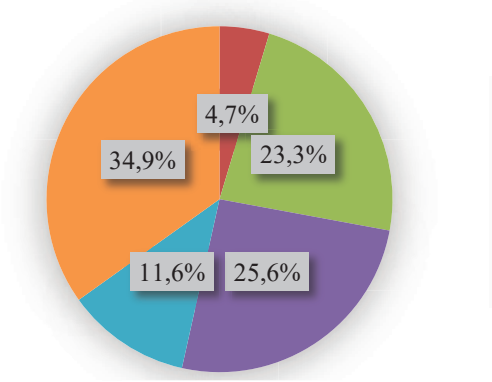

- Entre 31 e 35 anos

Entre 36 e 40 anos

- Entre 41 e 45 anos

Entre 46 e 50 anos

Acima de 51 anos

Fonte: dados da pesquisa.

Na Figura 1 se verificou a predominância de professores acima dos 40 anos. É importante comentar que, na pesquisa também havia espaço para, caso houvesse professores mais jovens, entre 20 e 30 anos, porém não houve respondentes para essa faixa etária.

Ainda, sobre o perfil dos participantes, buscou-se compreender qual é a escolaridade dos mesmos, conforme o gráfico da Figura 2.
Figura 2 - Perfil - Escolaridade dos participantes

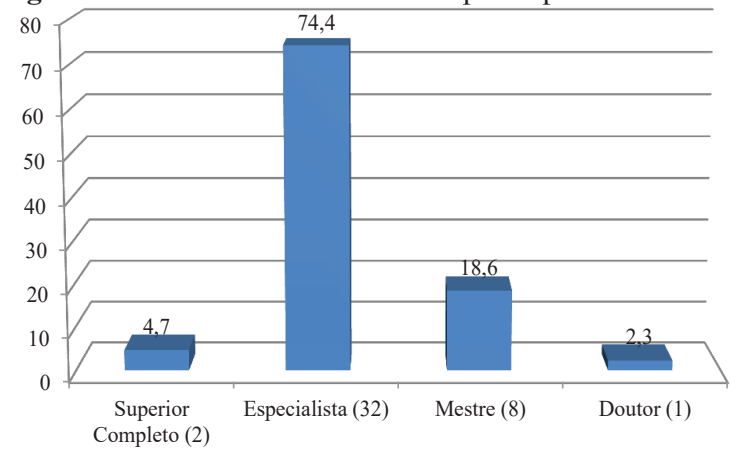

Fonte: dados da pesquisa.

De acordo com o gráfico da Figura 2 acima, é notável que a grande maioria dos docentes respondentes tenham escolaridade em nível de Especialização. Sendo que apenas um tem nível de doutorado, oito mestrado, e dois com apenas o Ensino Superior completo.

Junto aos dados coletados acima se observa que, no Brasil, apesar da grande necessidade de educação de qualidade, ainda são poucos aqueles que alcalçam formação com pósgraduação stricto sensu. É o que mostra o Censo da Educação Básica, no país em 2016 do total de 2.078.910 de professores na Educação Básica, apenas 747.249 tinham pós-graduação e, ainda, destes, 712.517 eram Especialistas, 30.690 Mestres e apenas 4.042 (5\%) Doutores (BRASIL, 2016).

\subsection{Categorias de análise}

Partindo para questões de conhecimento e noção acerca da legislação educacional, dos 43 professores participantes, $88,4 \%$ alegaram, em resposta a pergunta fechada ("Sim" ou "Não"), que tinham conhecimento sobre os documentos regulatórios de avaliação e currículo, e o que é requerido pelos mesmos com relação aos objetivos e competências. Ao passo que $11,6 \%$ disseram não ter esta ciência.

Essa orientação que a BNCC estabelece para nortear os currículos das escolas da Educação Básica, embasou a elaboração dos Referencial Curricular do Paraná e o CREP. Contudo, pelas respostas dos participantes, observa-se que $11,6 \%$ dos professores responderam que não conhecem os objetivos que se pretende atingir, bem como as competências que devem ser desenvolvidas no componente curricular de Educação Física para o Ensino Fundamental da rede pública estadual paranaense.

Por outro lado, o resultado também indica que a maioria dos professores entrevistados conhece os documentos reguladores que orientam a elaboração dos documentos, que norteiam o trabalho educativo proposto pela escola, neste caso, o Projeto Político Pedagógico, que especificamente apresenta em sua constituição a Proposta Pedagógica Curricular, a qual denota como a prática pedagógica será efetivada a partir das concepções assumidas coletivamente.

A prática pedagógica se efetiva a partir do conhecimento que compõe o currículo oficial ou explícito, pois o professor 
deverá selecionar, ordenar e definir as unidades temáticas, objetos de aprendizagem e habilidades para o componente curricular, neste caso, a Educação Física. Dessa forma, observa-se a partir do resultado do gráfico da Figura 1 que, possivelmente, o professor conheça os documentos regulatórios da Educação Pública do Estado do Paraná, em outras palavras, o Referencial Curricular do Paraná e o CREP.

$\mathrm{Na}$ esteira dessa discussão se infere, portanto, que o professor conhece os fundamentos conceituais, metodológicos e avaliativos do componente curricular Educação Física, sistematizados na Proposta Pedagógica Curricular e elencados na Matriz Curricular, os quais dão suporte para a ação docente em suas aulas práticas, aspecto evidenciado tanto no currículo oculto quanto no currículo real ou manifesto, por meio do seu Plano de Trabalho Docente, no qual se planeja a sua ação no que diz respeito à seleção do conteúdo, os objetivos, encaminhamentos metodológicos, os recursos didáticos, os instrumentos e os critérios de avaliação, evidentemente, em consonância com a Proposta Pedagógica Curricular.

A respeito disso se constata, em algum grau, certa contradição entre o referido conhecimento dos professores sobre competências/objetivos requeridos para o Ensino Fundamental da Rede Estadual Paranaense e o relato dos professores sobre o que conhecem sobre as competências requeridas nos documentos reguladores.

Conforme já posto se está assumindo que o conceito de competências está imbricado com a definição de conteúdos proposta por Coll et. al (2000 apud DARIDO; RANGEL, 2011), e compreende dimensões, sendo essas: conceitual, procedimental e atitudinal. Logo, é preciso que ainda sejam mobilizados saberes, a fim de serem desenvolvidas competências e, para isso é premente que sejam contempladas as habilidades práticas, cognitivas e socioemocionais, bem como acionadas as atitude e valores para resolver demandas complexas da vida cotidiana, e isso independe de se estar trabalhando com as dimensões conceituais ou procedimentais (BRASIL, 2018).

No Quadro 1, apresentado a seguir, tem-se a pergunta que ancora essa categoria, na qual foi solicitado que, aqueles que declaram possuir este conhecimento versassem, brevemente, sobre o que conhecem. Assim, obteve-se a devolutiva de 32 respostas a este questionamento.

Quadro 1 - Relatos dos professores sobre o que conhecem sobre as competências requeridas nos documentos reguladores

\begin{tabular}{|c|c|}
\hline Professor & Comentário \\
\hline P1 & $\begin{array}{l}\text { A competência, que prioriza a aula de Educação Física, é a consciência corporal. O aluno que tem dificuldade nessa } \\
\text { competência tem que reorganizar seus movimentos. A construção deve permear um processo de integração do } \\
\text { movimento, com a memória afetiva, reprodução e superação. São várias as competências, mas essa que mais priorizo. } \\
\text { Dou condições ao aluno de superação. Integrá-lo ao convívio com outros sem restrições ao seu movimento. Gera } \\
\text { conforto, socialização e respeito aos limites do outro. Chamo, assim, de cidadania! Oportunizar ao convívio social, sem } \\
\text { preconceito, trazendo o lúdico ao esporte, como gosto final. }\end{array}$ \\
\hline $\mathrm{P} 2$ & Proporcionar .... Realizar ... compreender. \\
\hline P3 & Neste momento, a inserção do CREP, novas metodologias. \\
\hline P4 & Desenvolve os aspectos cognitivos, motores e sociais. \\
\hline P5 & $\begin{array}{l}\text { As competências que estão dentro do PPP das escolas estão também ligadas à realidade e aos objetivos requeridos aos } \\
\text { alunos são inseridos, conforme a realidade da comunidade onde trabalho. }\end{array}$ \\
\hline P6 & A BNCC que entrou em vigor na prática esse ano de 2020 estabelece para etapa e ano habilidades específicas e gerais. \\
\hline P7 & Competências e habilidades de acordo com cada conteúdo. Podem ser motores, afetivos e psicossociais. \\
\hline P8 & Cada vez mais traz aprimoramentos aos alunos. \\
\hline P9 & $\begin{array}{l}\text { Compreensão do movimento humano intencional nas diversas manifestações como esporte, lutas, jogos, ginástica e } \\
\text { dança. }\end{array}$ \\
\hline $\mathrm{P} 10$ & Atualmente, começamos a trabalhar com o Crep. \\
\hline P11 & $\begin{array}{l}\text { Apesar de não concordar com o "saber fazer" do ensino por competência, busco a aproximação nas aulas com a } \\
\text { pedagogia histórico-crítica }\end{array}$ \\
\hline P12 & Base Nacional Comum Curricular e o CREP definiram essas competências e habilidades. \\
\hline P13 & $\begin{array}{l}\text { Proporcionar uma vivência teórica e prática sobre a cultural dos movimentos corporais. Promover interesse pela prática } \\
\text { de atividade física para a promoção da saúde. Respeito as regras das modalidades e aos limites dos colegas. Melhorar } \\
\text { a integração e cooperação do coletivo. }\end{array}$ \\
\hline P14 & Avaliação diagnóstica no início para conhecer o aluno. Conhecer essas competências para cada ano do Ensino Básico. \\
\hline P15 & $\begin{array}{l}\text { A preparação para o exercício da cidadania através dos seus conteúdos prático/teórico, onde os conteúdos não têm fim } \\
\text { em si mesmo. }\end{array}$ \\
\hline P16 & $\begin{array}{l}\text { Segundo o último documento orientador do estado (Referencial Curricular do Paraná), com base na BNCC (2017), os } \\
\text { objetivos e competências gerais deve seguir o seguinte tripé: Obter conhecimento (conceitos); Habilidades (práticas, } \\
\text { cognitivas e socioemocionais) e Atitudes e Valores. Em suma esta é a definição de Competências segundo a Base } \\
\text { Nacional Curricular Comum (BNCC). }\end{array}$ \\
\hline P17 & $\begin{array}{l}\text { O Crep - adotado este ano está muito difícil, pois os conteúdos adotados nas escolas fica impossível realizar essas } \\
\text { atividades. }\end{array}$ \\
\hline P18 & As competências e/ou objetivos constam nos documentos, tais como BNCC, CREP, etc. \\
\hline P19 & Sigo as normativas da BNCC e da DCE do Paraná, Cadernos Temáticos dos temas transversais- Paraná. \\
\hline
\end{tabular}




\begin{tabular}{|c|c|}
\hline Professor & Comentário \\
\hline P20 & $\begin{array}{l}\text { (Re) conhecer, vivenciar, compreender e analisar criticamente a função social de cada um dos conteúdos estruturantes } \\
\text { (esportes, jogos e brincadeiras, ginástica, lutas e danças) é o que se espera que o aluno seja capaz de fazer a partir das } \\
\text { aulas de Educação Física. }\end{array}$ \\
\hline P21 & Acompanho a nova Bncc e os parâmetros do Paraná. \\
\hline $\mathrm{P} 22$ & $\begin{array}{l}\text { As aulas são pensadas em estratégias para atingir os objetivos propostos para a aula, portanto existe a intencionalidade } \\
\text { pedagógica nas atividades. }\end{array}$ \\
\hline $\mathrm{P} 23$ & Ao final do ano letivo o aluno deverá dominar estas habilidades ou competências apresentadas. \\
\hline $\mathrm{P} 24$ & $\begin{array}{l}\text { Cabe aos alunos a interação com o universo escolar e seu ambiente social e afetivo, bem como dos conhecimentos } \\
\text { apropriados, advindo de suas experiências em comunidade e inseridas na Escola. Também é pertinente aos alunos } \\
\text { estarem se apropriando de práticas corporais que sejam motivacionais para a obtenção de hábitos saudáveis, tanto } \\
\text { físicos como psicológicos. Cabe também a nossos alunos estarem compartilhando nas aulas de educação física a } \\
\text { materialidade histórica de movimentos já estruturados, cuja intencionalidade é permeada por valores, que na sua } \\
\text { compreensão auxiliam nas questões da diversidade e equidade. }\end{array}$ \\
\hline $\mathrm{P} 25$ & $\begin{array}{l}\text { Além dos benefícios físicos, podemos desenvolver as habilidades sociais, motoras, cognitivas. Compreensão da cultura } \\
\text { corporal de movimento como parte integral da organização da vida coletiva e individual. Reflexão crítica acerca das } \\
\text { relações do nosso corpo e construção deste com o mundo. }\end{array}$ \\
\hline P26 & $\begin{array}{l}\text { Atualmente, minha avaliação tem por objetivo verificar se meu aluno é capaz de compreender, criar, realizar, participar } \\
\text { de atividades e exercícios corporais diversos, com atitudes de convivência harmoniosas, sendo capaz de reconhecer e } \\
\text { respeitar suas próprias características, desempenho próprio, e de seus colegas }\end{array}$ \\
\hline P27 & Atualmente temos uma diretriz estadual pautada na bncc. Estes documentos orientam o currículo do colégio. \\
\hline $\mathrm{P} 28$ & $\begin{array}{l}\text { Sim, na parte física despertar no estudante a importância das atividades físicas seja por meio de esportes, ginástica, } \\
\text { dança etc p ele ter conhecimento do seu corpo e poder cuida lo, e ser sempre uma pessoa ativa ao longo de sua vida ,na } \\
\text { parte psicológica desenvolver o respeito e cooperação ao próximo, organização em casa e no trabalho e etc }\end{array}$ \\
\hline P29 & $\begin{array}{l}\text { Na rede pública estadual seguimos para o fundamental anos finais o CREP que é uma proposta que busca a compreensão } \\
\text { de vários elementos que formam o conhecimento geral em torno do conteúdo selecionado. }\end{array}$ \\
\hline P30 & $\begin{array}{l}\text { Meu trabalho é voltado no documento do Currículo da Rede Estadual Paranaense (CREP) que traçam uma linha } \\
\text { sequente e gradativa, para que os estudantes adquiram conhecimento e repertório cultural, desenvolvam o pensamento } \\
\text { científico, crítico e criativo, a comunicação, a cultura digital, a argumentação, compreendam as relações entre trabalho } \\
\text { e projeto de vida e aprimorem o autoconhecimento, o auto cuidado, a empatia e a cooperação, tornando se cidadãos } \\
\text { responsáveis capazes de atuar na sociedade. }\end{array}$ \\
\hline P31 & Através da participação os mesmos têm uma reação extraordinária culminando até atletas. \\
\hline P32 & $\begin{array}{l}\text { Procuro elaborar o Plano de Trabalho Docente a partir dos documentos (BNCC, DCE's, Caderno de Expectativas de } \\
\text { Aprendizagem, e Currículo da Rede Estadual Paranaense) estabelecendo os objetivos/critérios a serem atingidos. }\end{array}$ \\
\hline
\end{tabular}

Fonte: Dados da pesquisa.

Entre as asserções que buscam relatar o conhecimento dos professores sobre as competências requeridas nos documentos regulatórios se destacam as seguintes:

P3: Neste momento, a inserção do CREP, novas metodologias; P6: A BNCC que entrou em vigor na prática esse ano de 2020 estabelece para etapa e ano habilidades específicas e gerais; P10: Atualmente começamos a trabalhar com o Crep;

P12: Base Nacional Comum Curricular e o CREP definiram essas competências e habilidades;

P17: O Crep - adotado este ano está muito difícil pois os conteúdos adotados nas escolas fica impossível realizar essas atividades;

P18: As competências e/ou objetivos constam no s documentos, tais como BNCC, CREP, etc.;

P19: Sigo as normativas da BNCC e da DCE do Paraná, Cadernos Temáticos dos temas transversais- Paraná;

P21: Acompanho a nova Bncc e os parâmetros do Paraná;

P27: Atualmente temos uma diretriz estadual pautada na bncc. Estes documentos orientam o currículo do colégio;

P29: Na rede pública estadual seguimos para o fundamental anos finais o CREP que é uma proposta que busca a compreensão de vários elementos que formam o conhecimento geral em torno do conteúdo selecionado;

P32: Procuro elaborar o Plano de Trabalho Docente a partir dos documentos (BNCC, DCE's, Caderno de Expectativas de Aprendizagem, e Currículo da Rede Estadual Paranaense) estabelecendo os objetivos/critérios a serem atingidos.

Nos enunciados se observa que os professores, de maneira geral, relacionam as competências a serem desenvolvidas com as diretrizes e documentos normativos. Em algumas asserções, por exemplo, P12 e P18, os participantes citam que nos documentos regulatórios são descritas as competências que devem ser desenvolvidas a partir do ensino e aprendizagem da Educação Física.

Na maior parte das asserções, são citados os documentos regulatórios, com ênfase para a $\mathrm{BNCC}$ e o CREP, conforme ocorre em P3, P6, P10, P12, P16, P17, P18, P19, P21, P27, P29, P30, P32.

Destaca-se, também, em P6, certa confusão entre competência e habilidade, a dificuldade de efetivar a prática pedagógica com base nesses documentos e a importância de segui-los para elaborar o plano de trabalho docente, segunda e décima primeira asserção, respectivamente, conforme P6 e P32.

A partir do excertos das enunciações dos participantes, foi possível investigar proposições que expessam a concepção dos professores sobre as competências e que fazem menção às dimensões do conhecimento, como segue:

P2: Proporcionar .... Realizar ... compreender.;

P16: Segundo o último documento orientador do estado (Referencial Curricular do Paraná), com base na BNCC (2017), os objetivos e competências gerais deve seguir o 
seguinte tripé: Obter conhecimento (conceitos); Habilidades (práticas, cognitivas e socioemocionais) e Atitudes e Valores. Em suma esta é a definição de Competências segundo a Base Nacional Curricular Comum (BNCC);

P26: Atualmente, minha avaliação tem por objetivo verificar se meu aluno é capaz de compreender, criar, realizar, participar de atividades e exercícios corporais diversos, com atitudes de convivência harmoniosas, sendo capaz de reconhecer e respeitar suas próprias características, desempenho próprio, e de seus colegas.

Em P16, o professor investigado conceitua competência de acordo com a BNCC, contudo, não relata como mobilizar o conhecimento no componente curricular - Educação Física. Em P2, o professor descreve uma maneira de abordar o conteúdo referente às supostas dimensões do conhecimento. E por fim, o relato de $\mathrm{P} 26$ cita o processo de avaliação do processo ensino e aprendizagem com ênfase nas habilidades, atitudes e valores, que estão imbricados nas competências da Educação Física.

Dentro dessa mesma categoria de análise se observou que os professores investigados relatam determinada relação com abordagem pedagógica e a didática para se atingir os objetivos da Educação Física. Como segue:

P5: As competências que estão dentro do PPP das escolas estão também ligadas a realidade e os objetivos requeridos aos alunos são inserido conforme a realidade da comunidade onde trabalho;

P11: Apesar de não concordar com o 'saber fazer' do ensino por competência, busco a aproximação nas aulas com a pedagogia histórico-crítica;

P14: Avaliação diagnóstica no início para conhecer o aluno. Conhecer essas competências para cada ano do ensino básico; P22: As aulas são pensadas em estratégias para atingir os objetivos propostos para a aula, portanto existe a intencionalidade pedagógica nas atividades.

É possível verificar que estão explícitos nos relatos a necessidade de diagnosticar os conhecimentos prévios do aluno e de adequar a prática pedagógica com sua realidade, pressupondo que esta abordagem é realizada a fim de se atingir os objetivos de aprendizagem propostos, ação que está em consonância com alguns passos da Pedagogia HistóricoCrítica (GASPARIN, 2007), bem como com os estudos de Kenski, Oliveira e Clementino (2006), Hoffmann, (2009) e Luckesi, (2011). Contudo, os enunciados não remetem, em momento algum, a relação de suas práticas com o desenvolvimento das competências descritas no documentos regulatórios.

Ainda, em relação à categoria de análise em questão, foi possível destacar asserções dos professores investigados que, de forma geral, apresentam alguma relação entre o conhecimento sobre as competências e sua suposta prática docente, mediante o relato descrito.

P1: A competência que prioriza a aula de Educação Física, é a consciência corporal. O aluno que tem dificuldade nessa competência, temos que reorganizar seus movimentos. A construção deve permear um processo de integração do movimento, com a memória afetiva, reprodução e superação. São várias as competências, mas essa que mais priorizo. Dou condições ao aluno de superação. Integra-lo ao convívio com outros sem restrições ao seu movimento. Gera conforto, socialização e respeito aos limites do outro. Chamo assim, de cidadania! Oportunizar ao convívio social, sem preconceito, trazendo o lúdico ao esporte, como gosto final.;

P9: Compreensão do movimento humano intencional nas diversas manifestações como esporte, lutas, jogos, ginástica e dança.

P13: Proporcionar uma vivência teórica e prática sobre a cultural dos movimentos corporais. Promover interesse pela prática de atividade física para a promoção da saúde. Respeito as regras das modalidades e aos limites dos colegas. Melhorar a integração e cooperação do coletivo.;

P15: A preparação para o exercício da cidadania através dos seus conteúdos prático/teórico, onde os conteúdos não têm fim em si mesmo;

P20: (Re) conhecer, vivenciar, compreender e analisar criticamente a função social de cada um dos conteúdos estruturantes (esportes, jogos e brincadeiras, ginástica, lutas e danças) é o que se espera que o aluno seja capaz de fazer a partir das aulas de Educação Física;

P24: Cabe aos alunos a interação com o universo escolar e seu ambiente social e afetivo, bem como dos conhecimentos apropriados, advindo de suas experiências em comunidade e inseridas na Escola. Também é pertinente aos alunos estarem se apropriando de práticas corporais que sejam motivacionais para a obtenção de hábitos saudáveis, tanto físicos como psicológicos. Cabe também a nossos alunos estarem compartilhando nas aulas de educação física a materialidade histórica de movimentos já estruturados, cuja intencionalidade é permeada por valores, que na sua compreensão auxiliam nas questões da diversidade e equidade;

P25: Além dos benefícios físicos, podemos desenvolver as habilidades sociais, motoras, cognitivas. Compreensão da cultura corporal de movimento como parte integral da organização da vida coletiva e individual. Reflexão crítica acerca das relações do nosso corpo e construção deste com o mundo;

P28: Sim, na parte física despertar no estudante a importância das atividades físicas seja por meio de esportes, ginástica, dança etc $\mathrm{p}$ ele ter conhecimento do seu corpo e poder cuida lo , e ser sempre uma pessoa ativa ao longo de sua vida ,na parte psicológica desenvolver o respeito e cooperação ao próximo, organização em casa e no trabalho e etc.;

P30: Meu trabalho é voltado no documento do Currículo da Rede Estadual Paranaense (CREP) que traçam uma linha sequente e gradativa, para que os estudantes adquiram conhecimento e repertório cultural, desenvolvam o pensamento científico, crítico e criativo, a comunicação, a cultura digital, a argumentação, compreendam as relações entre trabalho e projeto de vida e aprimorem o autoconhecimento, o auto cuidado, a empatia e a cooperação, tornando se cidadãos responsáveis capazes de atuar na sociedade.

Embora os professores não tenham relatado, de maneira específica, pode-se constatar que alguns descrevem o objeto de estudo e ensino da Educação Física, uma vez que citam excertos relacionados à cultura corporal de movimento, atrelados ao desenvolvimento das competências deste componente curricular, como por exemplo, em P20, P24 e P30.

Nesse sentido, para que os estudantes produzam conhecimento acerca deste objeto de estudo é fundamental que as habilidades específicas de cada objeto de conhecimento sejam ensinadas e apreendidas, a fim de atingir os objetivos subjacentes e, assim, desenvolver as dez competências da Educação Física para o Ensino Fundamental, logo o professor deve ter consciência destes aspectos, conforme apregoado pela BNCC (BRASIL, 2018). 
Nesse sentido, vale lembrar que a Educação Física como os outros componentes curriculares da BNCC, estão abarcados em áreas de conhecimento, a fim de atuarem de maneira conjunta, coerente e concisa para desenvolver as dez competências gerais da BNCC.

Nas asserções dos professores investigados se pode verificar que são realizadas menções a essas competências. Por exemplo, em P30 - "para que os estudantes adquiram conhecimento e repertório cultural, desenvolvam o pensamento científico, crítico e criativo, a comunicação, a cultura digital, a argumentação, compreendam as relações entre trabalho e projeto de vida e aprimorem o autoconhecimento, o autocuidado, a empatia e a cooperação, tornando-se cidadãos responsáveis capazes de atuar na sociedade." É evidente a inter-relação entre as competências do componente curricular - Educação Física, área de conhecimento - Linguagens e as competências gerais da Educação Básica.

Em P20, P25 e P30 são listados aspectos importantes, com relação à oportunizar aos alunos condições para refletir criticamente sobre as práticas corporais, neste ponto, o estudante é conduzido a adotar o pensamento científico, crítico e criativo.

Algumas asserções abordam pontos específicos de algumas competências da Educação Física como a compreensão da origem da cultura corporal de movimentos e seus vínculos com a organização da vida coletiva e individual, a ampliação do acervo cultural nesse campo, a valorização do trabalho coletivo e o protagonismo, o respeito à diversidade sem preconceitos e o exercício da cidadania. São exemplos de fragmentos descritos nos relatos:

P1: Gera conforto, socialização e respeito aos limites do outro. Chamo assim, de cidadania! Oportunizar ao convívio social, sem preconceito, trazendo o lúdico ao esporte, como gosto final;

P13: Melhorar a integração e cooperação do coletivo;

P15: A preparação para o exercício da cidadania através dos seus conteúdos prático/teórico, onde os conteúdos não têm fim em si mesmo;

P24: Cabe também a nossos alunos estarem compartilhando nas aulas de educação física a materialidade histórica de movimentos já estruturados, cuja intencionalidade é permeada por valores, que na sua compreensão auxiliam nas questões da diversidade e equidade;

P25: Compreensão da cultura corporal de movimento como parte integral da organização da vida coletiva e individual; P30: Compreendam as relações entre trabalho e projeto de vida e aprimorem o autoconhecimento , o auto cuidado, a empatia e a cooperação, tornando se cidadãos responsáveis capazes de atuar na sociedade.

Outro importante aspecto identificado na categoria de análise sobre o conhecimento dos professores sobre as competências requeridas nos documentos regulatórios, versa sobre proporcionar ao estudante o seu pleno desenvolvimento. Nesta perspectiva, foram observadas nas asserções a seguir que os professores investigados têm essa concepção de vislumbrar condições para o desenvolvimento do estudante nas esferas motoras, cognitivas e socioemocionais.
P4: Desenvolve os aspectos cognitivos, motores e sociais; P7: Competências e habilidades de acordo com cada conteúdo. Podem ser motores, afetivos e psicossociais; P25: Além dos benefícios físicos, podemos desenvolver as habilidades sociais, motoras, cognitivas. Compreensão da cultura corporal de movimento como parte integral da organização da vida coletiva e individual. Reflexão crítica acerca das relações do nosso corpo e construção deste com o mundo.

Em contrapartida, apesar de ser um número reduzido, alguns professores investigados apresentam, em suas asserções, construções vagas sobre o conhecimento de como desenvolver as competências da Educação Física para o Ensino Fundamental, conforme pode ser apreciado abaixo:

P8: Cada vez mais traz aprimoramentos aos alunos;

P23: Ao final do ano letivo o aluno deverá dominar estas habilidades ou competências apresentadas;

P31: Através da participação os mesmos têm uma reação extraordinária culminando até atletas.

Com relação a isso, Freire (1996, p.116) é categórico ao escrever que:

tão importante quanto o ensino dos conteúdos é a minha coerência de classe. A coerência, entre o que digo, o que escrevo e o que faço.

E ainda, corroborando com essa afirmativa, Luckesi (2011, p.132) assevera que, no que diz respeito à prática pedagógica escolar, o educador tem papel de executor, partindo do pressuposto que toda ação necessita de um executor, e que a execução de algo efetivo precisa de um executor consciente do que faz e de onde quer chegar e que, sem ele, o Projeto Político-Pedagógico de uma escola "não irá à prática, pois, para produzir resultados, precisa ser executado. A fim de cumprir suas finalidades, as intenções necessitam de ação efetiva" ou "coerente", como diria Freire (1996).

\section{Conclusão}

Iniciou-se o percurso de investigação, a fim de mapear a visão dos professores sobre os objetivos e competências requeridas nos principais documentos regulatórios, no que tange à avaliação nas aulas práticas. Para tanto, se foi a campo e procedeu uma pesquisa junto aos professores, que atuam com a disciplina de Educação Física, na Educação Básica, no Norte do Estado do Paraná.

Enquanto documentos regulatórios foram eleitos a BNCC, documento norteador nacional e os documentos que estão relacionados à Rede Estadual de ensino do Estado do Paraná, ou seja, as DCE e o Referencial Curricular do Paraná, Currículo da Rede Estadual do Paraná (CREP).

Após a análise dos excertos, no que tange às categorias de análise, sintetizaram-se os resultados: (a) discurso do professor versus documentos regulatórios do Estado do Paraná: observando-se que o discurso que o professor enuncia necessidade de conhecimento, com relação aos documentos regulatórios do Estado do Paraná; (b) competência profissional na aula prática: os dados apontam que a atuação do professor 
depende de ele conhecer teorias e práticas que subsidiem suas ações nas aulas práticas de Educação Física.

No que se refere à avaliação e currículo para a Educação Básica, identifica-se um confronto entre teoria e prática, logo, se torna fundamental averiguar se as premissas estabelecidas pelo Governo estão sendo atendidas na prática docente cotidiana, além de buscar compreender como, dentro de sua subjetividade, cada professor a compreende e aplica. Sugere-se, ainda, a verificação da eficiência da aplicação dessas premissas, bem como a eficácia das mesmas nos resultados produzidos pela escola, professores, alunos e demais envolvidos, frente aos objetivos e competências preestabelecidos.

A partir do mapeamento acerca das ideias e concepções particulares de um grupo de professores, junto aos aspectos importantes dos documentos e suas premissas, é possível e necessário (re)pensar, refletir, questionar até que nível os mecanismos e estratégias de aplicação do currículo e avaliação da aprendizagem, adotados pelos docentes, com base nos documentos regulatórios, contribuem na formação de alunos cidadãos, melhores preparados para a sociedade e para ações de cidadania.

Enfim, é preciso que as políticas educacionais de formação inicial e continuada de professores estejam centradas em oferecer condições para o professor acessar e produzir conhecimento teórico/prático, que o conduza a compreensão da necessidade de conhecer e desenvolver competências e habilidades, para resolver problemas de situações reais do cotidiano da prática docente para, enfim, cumprir a sua função social. A despeito disso, não se pode deixar de mencionar que as estruturas físicas e de recursos didáticos são condições objetivas para que o professor consiga atender os objetivos educacionais vigentes nos documentos regulatórios, por isso se defende que sejam consideradas as metodologias possíveis, dentro das condições efetivamente disponíveis.

\section{Referências}

BARDIN, L. Análise de conteúdo. São Paulo: Edições 70, 2016.

BRASIL. Constituição da República Federativa do Brasil (1988). Brasília: Senado Federal, 1988.

BRASIL. Lei no 9.394, de 20 de dezembro de 1996. Estabelece as diretrizes e bases da educação nacional. Diário Oficial da União, Brasília, 23 de dezembro de 1996. Disponível em: http://www. planalto.gov.br/ccivil_03/leis/L9394.htm. Acesso em: 4 ago. 2020.

BRASIL. Base Nacional Comum Curricular (BNCC). Educação é a Base. Brasília: MEC, 2018.
BRASIL. Instituto Nacional de Estudos e Pesquisas Educacionais - INEP. Censo Escolar da Educação Básica 2016: caderno de instruções. Brasília: INEP, 2016.

BORTONI-RICARDO, S M. O professor pesquisador: introdução à pesquisa qualitativa. São Paulo: Parábola, 2008.

DARIDO, S. C.; SOUZA JÚNIOR, O. M. Educação Física na escola: implicações para a prática pedagógica. Rio de Janeiro: Guanabara Koogan, 2011.

DES. National curriculum: task group on assessment and testing: a report. Department of Education and Science and Welsh Office, 1987. Disponível em: http://www.educationengland.org.uk/ documents/pdfs/1988-TGAT-report.pdf. Acesso em: 15 jul. 2020.

FREIRE, P. Pedagogia da Autonomia: saberes necessários à prática educativa. São Paulo: Paz e Terra, 1996.

GASPARIN, J. L. Uma didática para a pedagogia históricocrítica. Campinas: Autores Associados, 2007.

HOFFMANN, J.M.L. Avaliação mediadora: uma prática em construção da pré-escola à universidade. Porto Alegre: Mediação, 2009.

LUCKESI, C. C. Avaliação da aprendizagem: componente do ato pedagógico. São Paulo: Cortez, 2011.

KENSKI, V.; OLIVEIRA, G.P.; CLEMENTINO, A. Avaliação em movimento: estratégias formativas em cursos online. In: SILVA, M.; SANTOS, E. Avaliação da aprendizagem on-line. São Paulo: Loyola, 2006. p. 88.

MARCONI, M.A.; LAKATOS, E.M. Fundamentos de metodologia científica. São Paulo: Atlas, 2003.

PALMA, A.P.T.; OLIVEIRA, A.A.B.O.; PALMA, J.A.V. Educação Física e a organização curricular: educação infantil, ensino fundamental, ensino médio. Londrina: Eduel, 2010.

PARANÁ. Currículo da Rede Estadual Paranaense - Educação Física. Paraná, PR: Secretaria de Estado da Educação do Paraná, 2019. Disponível em: http://www.educacao.pr.gov.br/ sites/default/arquivos_restritos/files/documento/2020-02/crep educacaofisica.pdf. Acesso em: 13 ago. 2020.

PARANÁ. Diretrizes Curriculares da Educação Básica Educação Física. Paraná, PR: Secretaria de Estado da Educação do Paraná, 2008. Disponível em: http://www.educacao.pr.gov. $\mathrm{br} /$ sites/default/arquivos_restritos/files/documento/2019-12/dce_ edf.pdf. Acesso em: 13 ago. 2020.

PARANÁ. Referencial Curricular do Paraná: princípios, direitos e orientações. Paraná, PR: Secretaria de Estado da Educação do Paraná, 2018. Disponível em: http://www.educadores.diaadia. pr.gov.br/arquivos/File/bncc/2018/referencial_curricular_ parana_cee.pdf. Acesso em: 13 ago. 2020.

SANTOS, W. Currículo e avaliação na Educação Física: práticas e saberes. In: SCHNEIDER, O. et al. Educação Física esporte e sociedade: temas emergentes. São Cristovão: Ed. da UFS, 2008. p. $87-10$.

SILVA, G.E.B.L. Mulheres e docência: fatores identitários da profissão docente Belo Horozonte: Universidade Federal de Minas Gerais, 2016. 